\title{
Text Message Collection and Processing System (TMCPS) to Facilitate Doctor and Patients
}

\author{
Hira Nazir \\ Department of Computer Science, Govt. SE \\ College Bahawalpur, Pakistan
}

\author{
Muhammad Samiullah \\ Department of Computer Science, Islamia \\ University Bahawalpur, Pakistan
}

\begin{abstract}
The purpose of this research is to develop a tool that is easy to manage by a doctor. Patient will be able to input his/ her details of disease as text message and get prescription or a token (date + number) depending on the symptoms of disease. Sometimes a patient cannot give extra details about his/ her symptoms on the spot, don't want to move physically for taking the number and time for checkup or the doctor becomes tired of listening to the patients. Moreover, there are doctors whose listening power are weak and cannot listen well. The text message collection centre will be a best solution to the above mentioned problems. The server will generate a report containing bar chart of patient's text messages sent to doctor(s) and a table containing patient id, patient name, patient mobile number, patient address, patient text message, doctor's code, and doctor's name. The text messages sent by different patients via Short Message Service (SMS) will be collected by a server. The server will accept only those text messages which contain valid doctor's code of a registered patient. We focused too much on software components and development rather than hardware components.
\end{abstract}

\section{Keywords}

Extraction, SMS, Token, Mobile Station, GSM modem

\section{INTRODUCTION}

We implemented the existing theory of global system for mobile communication (GSM); a standard wireless digital network of efficient and reliable communication [1] for sending/ receiving text message via short message service (SMS). Although email can be used for communication but email will be costly in communicating only text messages. The use of mobile phone is reliable as compared to internet as it is portable, available at less cost, easy to use, availability of SMS packages at very less cost and provides near real time short message service. As reported by Pakistan Telecommunications Authority (PTA) in September 2011, there are 108.89 million cellular subscribers in Pakistan as compared to 33.9 million in year 2006 as shown in the figure 1. Also the use of SMS for text messaging in Pakistan has a higher success rate of greater than $90 \%$ as shown in the figure 2. That's why we preferred Short Message Service (SMS) for text communication.

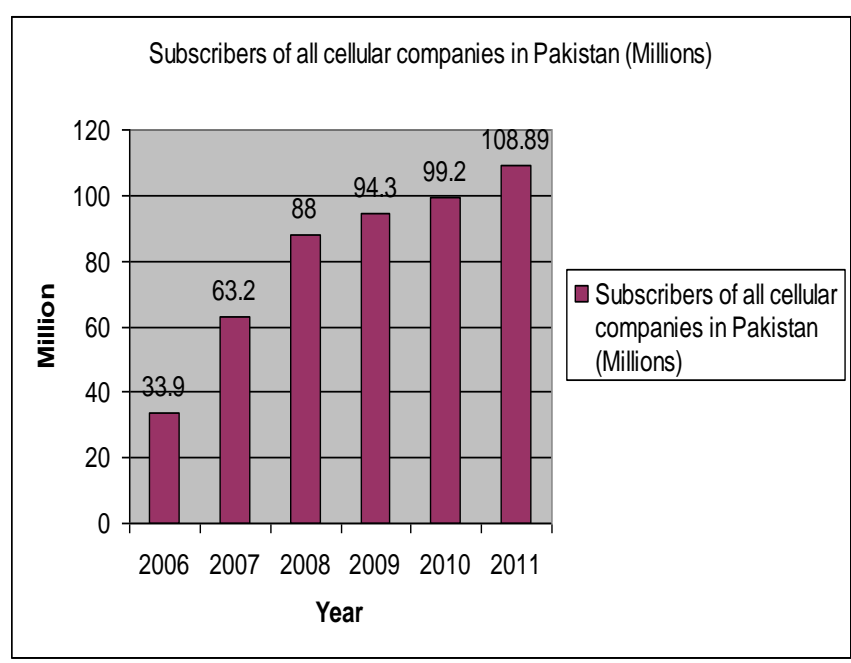

Figure 1: subscribers of cellular companies in pakistan (millions)

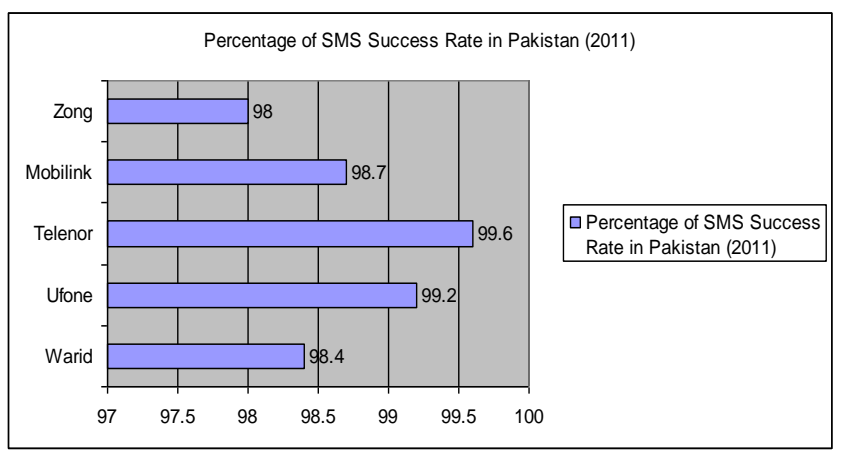

Figure 2:SMS success rate in pakistan

The TMCPS accepts the message by checking the valid doctor's code, checking the patient's registration. If the doctor's code is invalid or patient is not registered into the system, the server will reject the text message; otherwise the server will store it into the database for further processing and send a reply to the sender's/ patient's mobile station (mobile phone with SIM card). The reply consists of current date/ time and a unique number with some appropriate message such as welcome or thanks for using the service. Actually the reply from server is an appointment of patient's physical check up with the doctor for his/ her satisfaction. Otherwise the patient can get the prescription through SMS from the doctor by simply sending a text message containing a word PRESCRIBE following the symptoms of disease. 
(DR1) Last night I ate burger with cold drink. vomiting and diarrhea started. (PRESCRIBE)

The sample text message shown above sent by a patient consists of three parts as shown above. The first part is doctor's code for communication purpose, second part is the patient's detail about the disease and the third part is optional if third part is present then patient will receive prescription in the form of text message otherwise patient will have to move physically to the doctor's clinic/ hospital for his/ her checkup where patient will have to show the reply of the message sent by him. The server generates a report of all the messages stored into the database. The server classifies all the text messages according to the doctors and patients if there are more than one doctor in a hospital. PHP, My Sql with Dream weaver and Ozeki message server were used to develop the entire system.

The rest of the paper is organized as follows. The related work is presented in section II. Section III comprises of system architecture while section IV and V give the experiments/ results and conclusion respectively.

\section{2- RELATED WORK}

Many national and multinational companies use text messaging for direct marketing, promotional activities and to manage customer relationships [2]. Most of the organizations are putting their efforts on the topics such as device controlling, customer relationship management (CRM), mobile commerce and SMS based applications in educational and other institutions, for example see, [3][4][5]. Mobile Islamic Medication Expert System (MIMES) gives treatment of different diseases by sending SMS- containing Islamic verses [6]. This expert system uses Ozeki Message Server for sending/ receiving SMS, MySql for database and PHP for development. For accessing the expert system, user sends a text "Islamic Medi" via SMS. The expert system responds by sending a message- "Welcome to the Islamic Medication" on the user's message screen. At the same time another message is sent by MIMES which consists of different diseases. The sender selects one of the disease with symptoms and sends back it to the MIMES. The MIMES responds by sending a message containing names of different surah, the quantity of reading and the way of reading. The expert system is open to public, there is no need to register the people. There is no check and balance on the messages whether to store it in the database or not and no report generation as our system does filtering and stores only the valid format SMS of only registered patients. A web based diabetic patient management system developed by [7] that uses internet and SMS technology for communication between doctors and patients. DIABTel [8] a telemedicine service that takes care of diabetic patients by sending them the alerts, advises and preventions.

\section{3- SYSTEM ARCHITECTURE}

The purpose of this system is to ease the two nodes i.e doctor and patient along with sufficient management of patient's history through text messages. The hardware components for the smooth running of the system are:

1. Mobile Station (Mobile Phone with SIM Card )

\section{Personal Computer/ Laptop}

While the softwares to run this system include:

1. Microsoft Windows XP/ 7

2. Internet Explorer/ Opera or any other browser

Code generation for this system was made available in two languages; PHP and JSP by using Integrated Development Environment such as Macromedia Dreamweaver for efficient input and output handling. SMS receiving/ sending is done by the API provided by the Ozeki Message Server.

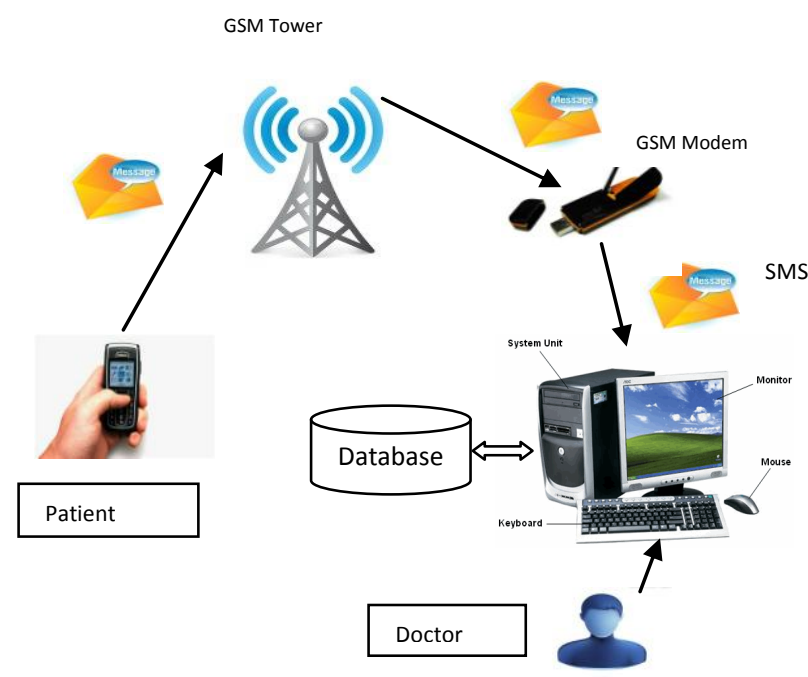

Figure 3: External Architecture of the System

The SMS module of this system is divided into the following sub modules:

1. Get SMS

2. Get mobile No.

3. Read SMS

4. Extract Code

5. Save SMS

6. Code Based Action

7. Discard SMS

\section{GSM Modem}


Except the above mentioned modules there is an admin module. In this module we can add, delete, update and view the login details of doctors. The doctor will use his/ her login details to login to the system. The SMS sent from the patient's mobile station is accepted by ozeki message server via GSM modem. GSM modem containing the SIM card is plugged into USB port of the computer. Patient will use this global SIM number (inserted into GSM modem) for communication purpose. All the text messages will be sent to this global SIM number. The ozeki message server on the other hand will take text message from GSM modem's SIM. Now our system will take the text messages from ozeki message server using our getsms() function. After getting the SMS, our system extracts sender's mobile number using our getpatientcell() function and checks whether the extracted mobile number is already registered in our database or not. If it is not available in the database then it simply discards the text message using deletemsgin() function. And if it is available in the system's database then our SMS read Module reads the contents of SMS data. During the read operation, code present in the SMS is extracted through getdoccode() as shown below:

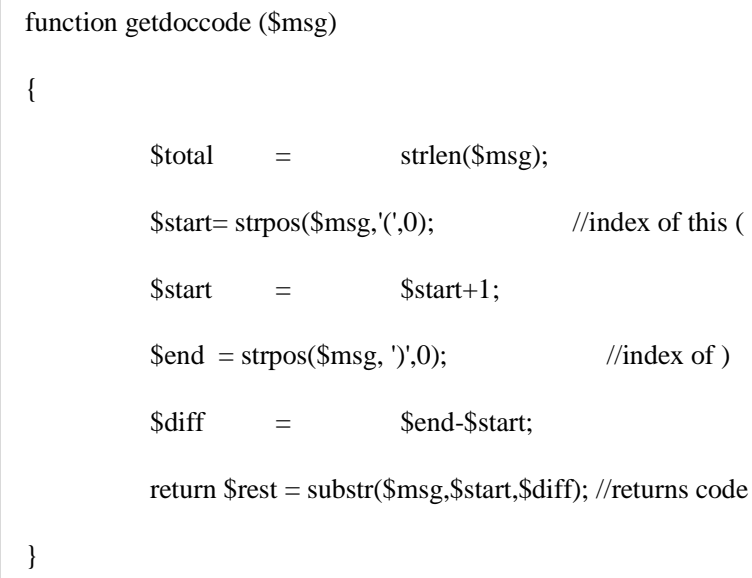

The extracted code is compared with the codes of the doctors present in the database. If the extracted code is matched with the code available in the database, then rest of the text message is extracted through getrestsms() function as shown below and an appropriate action will take place.

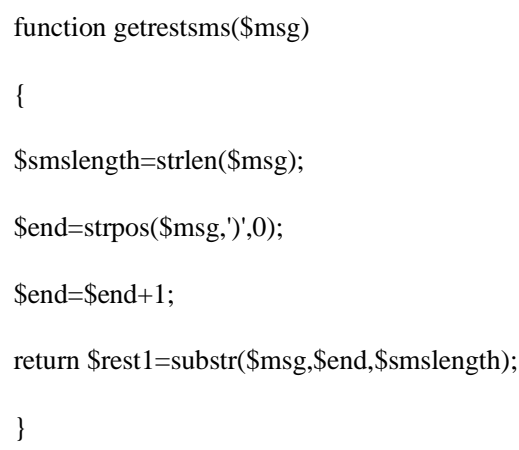

An appropriate action may be to create SMS report containing chart and a table of records in the following format:

\begin{tabular}{|c|c|c|c|c|c|}
\hline $\begin{array}{l}\text { Patient } \\
\text { Name }\end{array}$ & $\begin{array}{ll}\text { Patient } & \text { Cell } \\
\text { Number } & \end{array}$ & SMS & $\begin{array}{l}\text { Received } \\
\text { Date/Time }\end{array}$ & $\begin{array}{l}\text { Doctor's } \\
\text { Code } \\
\text { (Extracted } \\
\text { from the } \\
\text { SMS) }\end{array}$ & $\begin{array}{l}\text { Doctor's } \\
\text { Name }\end{array}$ \\
\hline Ahsan & +923326312324 & $\begin{array}{l}\text { I'm } \\
\text { Suffering } \\
\text { from } \\
\text { fever and } \\
\text { feeling } \\
\text { nausea } \\
\text { from } 2 \\
\text { days. } \\
\text { The } \\
\text { fever is } \\
102\end{array}$ & $\begin{array}{l}2011-08- \\
18 \\
18: 04: 05\end{array}$ & Dr101 & $\begin{array}{l}\text { Dr. Yasir } \\
\text { Irshad }\end{array}$ \\
\hline
\end{tabular}

Table 1: SMS Report Format

Sorting option has also been provided on SMS report. We can sort Text messages in ascending or descending order either by patient name, doctor's code, date/ time or doctor's name. A bar chart will be showing the information such as how many SMS sent by how many patients and to how many doctors.
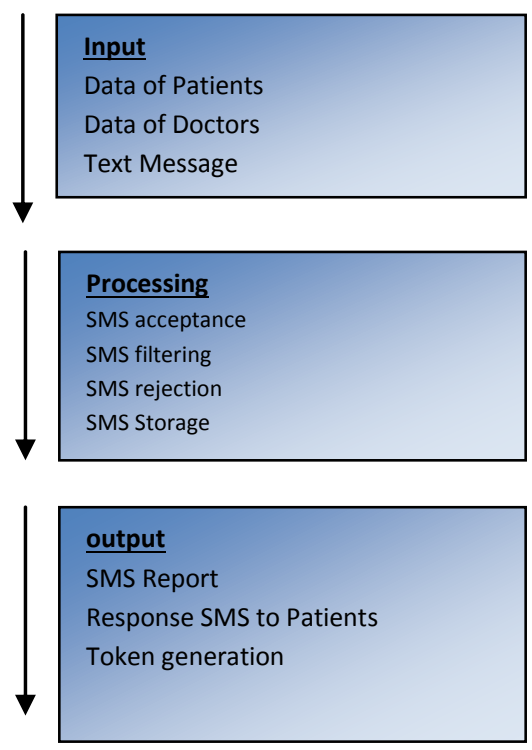

Figure 4: Internal Architecture

\section{4- Experiments and Results}

Out door Emergency hospital of Bahawalpur, Pakistan was used to test our system by registering a sample of 100 patients and 5 doctors by adding the attributes of doctors and their patients in the database. Doctors' code were also assigned to different doctors by using first two letters of first name and first letter of last name with some sequenced digit in the end, as shown in table 2 below. Registered patients were permitted to send text messages using the doctor's code. The average time taken by 20 groups (a group of 5 SMS sender) to reach in SMS server from patients was 9.31 seconds using mobilink network as shown in the figure 5 below. The time may vary because of the network conditions of different cellular companies. According to Pakistan Telecommunication Authority (PTA) report 2011, SMS end to end delivery is 8 $\mathrm{sec}, 8.7 \mathrm{sec}, 9.1 \mathrm{sec}, 15.5 \mathrm{sec}, 26.6 \mathrm{sec}$ using mobilink, warid, ufone, telenor and zong network respectively. In our 
experiment, 95\% SMS were received in first attempt and the remaining 5\% SMS received in second or third attempt. Almost all of the patients were responded by our system in the form of text messages containing prescriptions and welcome messages with token numbers. Here token number contains the date /time and sequenced number to meet the doctor for treatment. Figure 5 and 6 below represent the sent and received text messages and final SMS report of patients' sent to the respective doctors.

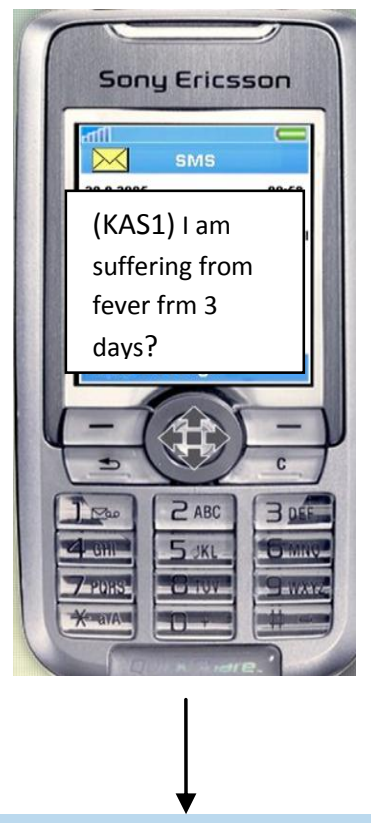

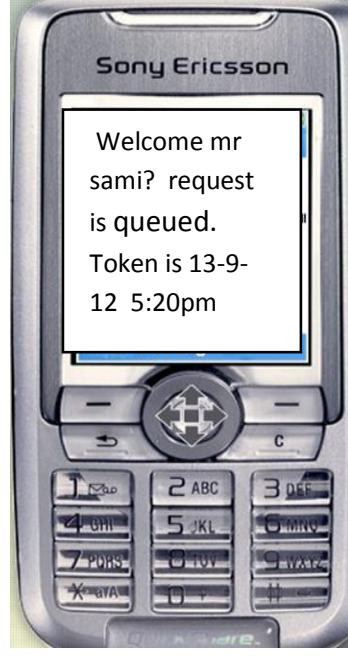

Fig 5: SMS sent and received by patient
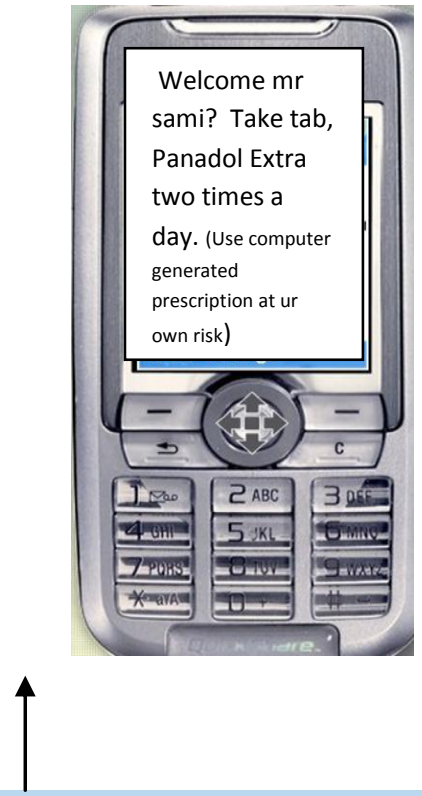

DOCTORS SECTION

Click Here To View Sms

\begin{tabular}{|c|c|c|c|c|c|c|c|}
\hline \multicolumn{2}{|c|}{ Student Name } & $v$ & & Searcl & & & \\
\hline$\square$ & $\begin{array}{l}\text { Patient } \\
\text { Name }\end{array}$ & Patient Cell No. & $\begin{array}{c}\text { Received } \\
\text { date }\end{array}$ & $\begin{array}{l}\text { Doctor } \\
\text { Name }\end{array}$ & $\begin{array}{l}\text { Doctor } \\
\text { Code }\end{array}$ & Message & Operation \\
\hline$\square$ & sami ullah & +923007817995 & $\begin{array}{c}2012-09-13 \\
04: 29: 50\end{array}$ & $\begin{array}{l}\text { KASHIF } \\
\text { SAEED }\end{array}$ & KAS1 & $\begin{array}{l}\text { Sir I used the } \\
\text { prescription no. } \\
13.09 .1204 .20 \text {. It } \\
\text { recovered me. } \\
\text { Thanks doctor. } \\
\text { GOD BLESS U. }\end{array}$ & $\boldsymbol{x}$ \\
\hline \multirow[t]{2}{*}{$\square$} & sami ullah & +923007817995 & $\begin{array}{c}2012-09-13 \\
04: 20: 32\end{array}$ & $\begin{array}{l}\text { KASHIF } \\
\text { SAEED }\end{array}$ & KAS1 & $\begin{array}{l}\text { im sufering frm } \\
\text { fever frm } 3 \text { days. } \\
\text { My temprature is } \\
101 . \text { Vomiting also } \\
\text { started today. Plz } \\
\text { give me time. }\end{array}$ & $\mathbf{x}$ \\
\hline & & \multicolumn{2}{|c|}{ Delete All } & & & & \\
\hline
\end{tabular}

Fig 6: SMS Report 


\section{5- CONCLUSION AND FUTURE WORK}

The text message collection and processing centre based on GSM- SMS technology is presented in this paper in which registered patients send their queries in the form of text messages to their doctors. The text consists of doctor's code with disease symptoms. On the arrival of message, system validates the patient's cell number from the database, validates the doctor's code by extracting it from the SMS, reads rest of the SMS and in response generates a welcome message followed by patient's name and token number that is sent to patient's mobile phone. Information messages about new medicines, diseases, health tips and warning messages such as preventive measures can be sent to its registered patients on just single mouse click. The patient will use this token to visit/ meet the doctor. On the other hand doctor's assistant can take a print out of the patients' messages received by the system to facilitate doctor to read out the symptoms of the patient while attending the patient. Future work includes making it more portable by developing a mobile application to use it on mobile device to facilitate the doctors. And interfacing it with MMS to include the pictures of allergic skin in the message.

\section{6- REFERENCES}

[1] Eberspacher, J. et al. (2009). GSM- Architecture, Protocols and Services. Third Edition. Germany: John Wiley \& Sons Ltd

[2] Frolick, M.N. and Chen, L.D. (2004), "Assessing mcommerce opportunities", Information Systems Management, Vol. 21 No. 2, pp. 53-61.

[3] Friel, D. Kilmartin, L. (June, 1998). "An automated stock price delivery system based on the GSM short message service", IEEE International Conference on Communications, (ICC98), vol. 3, pp. 1591 - 1595.

[4] Idris, A. Basri, A. Zubir, H.N. (2009). "An Application of SMS Technology for Customer Service Centre", International Conference of Soft Computing and Pattern Recognition. pp. 633-636.
[5] Krishnamurthy, N. (Dec, 2002). "Using SMS to deliver location-based services", IEEE International Conference on Personal Wireless Communications, pp. 177 - 181.

[6] Wan, K. (Nov. 2003). "An SMS-based sales reporting system for a fashionclothes franchising company, Managing Technologically Driven Organizations: The Human Side of Innovation and Change", Engineering Management Conference, 2003 (IEMC '03), pp. $330-$ 334.

[7] Bt Daud, H., Izaney, N., Jung, L.T., Ali, K.K. (2010). "Development of Islamic Medication Expert System on Mobile Platform (MIMES)", IEEE conference.

[8] Kwon, H. S. et al. (2004). "Development of web-based diabetic patient management system using short message service (SMS)", Diabetes Research and Clinical Practice. [online]. Available from: Http: Ilwww.sciencedirect.com [Accessed July, 2008].

[9] E. J. Gomez, F. Del Pozo, M. Hernando, (October 1996) "Telemedicine for diabetes care: The DIABTel approach towards diabetes telecare", Informatics for Health and Social Care, Volume 21, No. 4 pp. 283 - 295

\section{7- AUTHORS PROFILE}

Hira Nazir received BS (IT) degree in 2010 from department of computer sciences \& IT the Islamia university of Bahawalpur, Pakistan and was declared gold medalist with CGPA 4.56 equivalent to $90 \%$. Her research focus includes developing network security algorithms and SMS based secure applications.

Muhammad samiullah after completing his BS (CS) from the Islamia University of Bahawalpur, Pakistan in 2004, he did MBA (marketing) in 2007 and completed course work of MS (Computer Science) from the Islamia University of Bahawalpur, Pakistan in 2011. His research focus includes developing network security algorithms, SMS based applications and DNA computation. 